\title{
LA OTRA LEY DE FOUCAULT, UNA LECTURA CRÍTICA
}

\author{
Mauro Benente \\ Universidad de Buenos Aires / CONICET
}

http://dx.doi.org/10.5209/rev NOMA.2016.v47.n1.52394

\begin{abstract}
Resumen.- Son pocos los trabajos que han estudiado la relación entre la ley y el poder en la obra de Michel Foucault. Algunos autores remarcan que la ley cumple un rol completamente secundario en el diagrama de poder de la modernidad, mientras que otros sostienen que existe una íntima vinculación entre las relaciones de poder y la ley. Foucault's Law de Golder y Fitzpatrick pretende renovar estas discusiones y reconstruir otra ley de Foucault. En este trabajo realizaré una lectura crítica de esta obra, remarcando la defectuosa presentación que los autores realizan de la obra de Foucault.
\end{abstract}

Palabras clave: Derecho, poder disciplinario, gubernamentalidad, resistencia.

Abstract.- Few studies have addressed the relationship between law and power in the works of Michel Foucault. Some authors emphasize that law performs a completely secondary role in the diagram of power of modernity, while others argue that there is a close link between power relations and the law. Foucault's Law by Golden and Fitzpatrick aims to renew these discussions and reconstruct another law of Foucault. In this paper I make a critical reading of this work, highlighting the faulty presentation that the authors carried out of the works of Foucault.

Keywords: Law, disciplinary power, governmentality, resistence.

\section{Introducción}

Si bien los trabajos de Foucault han tenido una notable influencia en disciplinas como la filosofía, la teoría política, la sociología y la historiografía, y estamos frente a uno de los autores más trabajados en la actualidad, no abundan los estudios que tematicen sobre sus aportes al derecho.

Durante una década y media, las discusiones sobre la ley en la obra de Michel Foucault giraron en apoyo o en respuesta a los desarrollos de Foucault and Law. 
Towards a Sociology of Law as Governance publicado por Alan Hunt y Gary Wickham en 1994. Aclarar que data de 1994 no es un dato menor puesto que recién ese año se publicaron los Dits et écrits y faltaban tres años para que los cursos dictados en el Collège de France comenzaran a aparecer. Con anterioridad a esta publicación, François Ewald había dedicado algunos párrafos al tratamiento del derecho en la obra de Foucault, y con posterioridad se publicaron varios artículos, hasta que en 2009 apareció Foucault's Law de Ben Golder -profesor en la Universidad de New South Wales de Australia- y Peter Fitzpatrick -profesor en Birkbeck, Universidad de Londres-. Al año siguiente realizaron una compilación titulada Foucault and Law, en la que se incluyeron artículos ya publicados pero dispersos en diferentes revistas, y en el 2013 Golder compiló Re-reading Foucault: On Law, Power and Rights.

En el presente trabajo realizaré una breve presentación de la tesis de la expulsión enunciada por Hunt y Wickham, incluiré una reseña de artículos publicados con posteridad en diálogo con la tesis de la expulsión, y finalmente analizaré Foucault's Law. A diferencia de los trabajos precedentes, la labor de Golder y Fitzpatrick incluye un estudio integral de los trabajos de Foucault, rastreando huellas del derecho en libros, cursos, y en las entrevistas y artículos incluidos en los Dits et écrits. De todos modos, según diré, este mérito se diluye cuando caemos en la cuenta de la problemática, errónea, y por momentos tramposa presentación del autor francés material.

\section{La tesis de la expulsión y las de la inclusión}

Varios autores han postulado que Foucault expuso una muy limitada conceptualización de la ley, pero quienes han trabajado con mayor precisión esta temática han sido Alan Hunt y Gary Wickham, tanto de modo individual (Hunt, 1992a, 1992b, Wickham, 2002, 2006), cuanto en su obra conjunta Foucault and Law. Allí postulan que sistemáticamente Foucault "vincula la ley con la concepción negativa del poder de la cual se esfuerza por escapar" (Hunt, Wickham, 1994, p. 40). De este modo, adopta acríticamente la fórmula positivista según la cual la ley sería una regla acompañada de una sanción, y no logra constituir una mirada más sofisticada del funcionamiento del derecho (Hunt, Wickham, 1994, p. 41).

Para Foucault, lo distintivo de la modernidad es el funcionamiento disciplinario del poder, y las disciplinas y la ley constituyen "un proceso dual, pero opuesto" (Hunt, Wickham, 1994, p. 46). Como la ley mantiene un funcionamiento a partir de la represión y la prohibición, el funcionamiento de los mecanismos disciplinarios "es asegurado, no por la ley sino por la normalización” (Hunt, Wickham, 1994, p. 49). En este mismo orden de ideas Kennedy advierte que Foucault presenta una "discontinuidad radical entre el poder legal y el poder disciplinario" (1991, p. 356) y Hirst agrega que tiende a "contraponer la regulación legal y la regulación disciplinaria" (1986, p. 50) y por ello "la ley es marginada, las intervenciones legales devienen secundarias respecto a una masa de intervenciones normalizadoras" (1986, p. 50). Finalmente, para Boaventura de Sousa Santos "Foucault exagera una mutua incompatibilidad entre el poder jurídico y el poder disciplinario, y pasa por alto las profundas interpenetraciones entre ambos" (2002, p. 5). Si estos son los contornos de la tesis de la expulsión, son varias las tesis de la inclusión, puesto que 
con diversos argumentos se ha intentado mostrar, ya no la separación, sino la íntima vinculación entre la ley y los dispositivos de poder y gobierno.

En su lectura de la obra de Foucault, François Ewald estima que "la formación de la sociedad disciplinaria no redujo de ningún modo el poder de la ley" (1986a, p. 138) sino que se fue transformando en norma (1986b, p. 71, 1986c, p. 482). Además propone concebir a la norma como "ley social", práctica legal típica del Estado de bienestar, producto de acuerdos entre diferentes grupos sociales y con el objetivo de compensar las desigualdades (1986a, p. 40, 46, 48-49). Por su lado, en una reseña del trabajo de Hunt y Wickham, Beck subrayó que "la ley no fue excluida por las disciplinas: las dos son interdependientes" (1996, p. 493), y Tadros dirigió una fuerte crítica a la tesis de la expulsión, agregando que la ley actuaba como una bisagra entre los dispositivos disciplinarios y las tecnologías gubernamentales (1998, p. 99).

Hunt y Wickham (1994, pp. 99-116) sospechaban que los desarrollos sobre la gubernamentalidad podría reposicionar al derecho, y Tadros indicó que los dispositivos de la gubernamentalidad necesitaban de la ley, pero el trabajo más afinado en este punto es Governed by Law?, de Nikolas Rose y Mariana Valverde. Su argumento central no radica solamente en vincular al derecho con las prácticas gubernamentales, sino en sustituir la preocupación por el derecho por el "complejo legal" que alude a un conjunto de "prácticas legales, instituciones legales, estatutos, códigos legales, autoridades, discursos, textos, normas y formas de juicio" (1998, p. 542). Es así que en lugar de focalizarse solamente en la ley resulta urgente investigar "el rol del razonamiento legal, las autoridades legales, los foros legales y las técnicas legales en las prácticas de gobierno de las sociedades modernas" (1998, p. 543).

Si hasta aquí he presentado muy resumidamente la tesis de la expulsión y las tesis de la inclusión, desarrollaré con más detalle y precisión la lectura de Golder y Fitzpatrick, que marca una interesante novedad en los trabajos sobre el derecho en la obra de Foucault.

\section{La otra ley de Foucault}

Gran parte de la labor de Golder y Fitzpatrick se construye en oposición a la tesis de la expulsión, y si bien admiten que en algunas intervenciones Foucault indicó que en sociedades disciplinarias la ley retrocedía, en otros casos mostró solapamientos entre ella y las diferentes tecnologías de poder (2009, pp. 56-59). Sin embargo, asumir que la ley se mantiene como uno de los rasgos de la modernidad implica preguntarse qué relación existe con las formas de poder. Todas las lecturas oscilan entre: a- subordinar la ley a los dispositivos disciplinarios y/o mostrar que su lugar en el funcionamiento del poder es secundario; b- resituar su papel dentro las tecnologías modernas de poder. De todos modos en ninguna de estas perspectivas se advierte el doble plano que efectivamente presenta la ley en los trabajos de Foucault: una ambivalencia entre "una ley subordinada y una ley superadora [surpassing], entre una ley que es confinada por la emergencia del poder disciplinario y el biopoder, y una ley que es ilimitada y siempre yendo más allá de sí misma y de aquello que quiere instrumentarla" (2009, p. 39). Estas dos dimensiones de la ley, como determinada y como receptiva al exterior, no representa una contradicción sino que "Foucault está, de hecho, afirmando algo enteramente consistente -y muy apropiado- sobre la ley" (2009, p. 39). 
El funcionamiento de la ley no se puede limitar a una mera herramienta del poder soberano ni a un instrumento del poder disciplinario. Ella es "algo más", y es esto lo que los autores pretenden desentrañar: este movimiento de la ley que es confinada pero también sobrepasa a aquello que la quiere confinar es la "«lógica» identificable de la ley misma. Esta necesaria irresolución es constitutiva de la (des)unidad de la ley de Foucault" (2009, p. 53). Su carácter fijo y determinado, a la vez que ilimitado, son "dimensiones relacionadas de la misma ley" (2009, p. 53). Si bien hay una dimensión de la ley que se relaciona con los mecanismos de poder, hay algo que la hace abrirse a ser de otro modo y es esta "irresolución que percibimos como constitutiva de la ley en Foucault es, en sí mismo, una especie de resolución (de ahí irresolución)" (2009, p. 54). Empero, antes de avanzar sobre la irresolución y ambivalencia, Golder y Fitzpatrick reintroducen el análisis de la relación entre la ley y las tecnologías de poder.

Como punto de partida cabe destacar que en la obra de Foucault "la ley está frecuentemente ligada a algo más. Ella nunca parece existir en un grado de coherencia autosustentable o de inviolabilidad" (2009, p. 60). La ley se encuentra ligada a la formación de cuerpos de conocimiento y diferentes modalidades de poder, por lo que a contrapelo de algunas versiones del positivismo jurídico, que la conciben como una entidad autónoma y autosuficiente, la ley es descripta "en términos relacionales" (2009, p. 60), vinculada con los planos científicos, epistemológicos, y políticos. De hecho, de acuerdo con la lectura de Golder y Fitzpatrick, el objeto de estudio de Vigilar y Castigar es el análisis de "«las estructuras jurídico-políticas de la sociedad», su «modelo jurídico-político»" (2009, pp. 60-61). El entrecomillado que los autores citan, a primera vista parece confirmar que el blanco de análisis de Vigilar y castigar es la interconexión de la ley con otras variables -saber, poder, etcétera-. Lo que resulta extraño es el recorte de citas que realizan los autores para sustentar lo anterior. La primera de ellas, restituida de modo integral, indica que "la modalidad panóptica del poder -a nivel elemental, técnico, humildemente físico en que ella se sitúa- no está bajo [cursiva agregada] la inmediata dependencia y en la prolongación directa de las grandes estructuras jurídico-políticas de una sociedad" (Foucault, 1975, p. 223). Uno de los objetivos centrales de Vigilar y castigar es la descripción del poder disciplinario, que en varias oportunidades Foucault lo conceptualiza como modalidad panóptica del poder (2003, p. 81), por lo que no se entiende cómo de una frase en la cual separa expresamente el panoptismo de la estructura jurídico-política de la sociedad, Golder y Fitzpatrick observan que el análisis de esta última es el objeto de estudio del libro.

Similares problemas se advierten en la segunda referencia de Vigilar y castigar, que hay que contextualizar. Hacia el final de la sección sobre el panoptismo, Foucault postula que "el siglo XVIII ha inventado las técnicas de la disciplina y del examen, un poco, sin dudas, como la Edad Media ha inventado la investigación judicial" (1975, p. 226). El procedimiento de investigación judicial se desarrolló entre los siglos XVII y XIII en el marco de la reestructuración de la Iglesia y del ascenso de los Estados, oponiéndose a mecanismos de averiguación de la verdad como los juramentos, la ordalía, el duelo, y la transacción entre particulares. La investigación representaba al "poder soberano arrogándose el derecho de establecer la verdad por medio de cierto número de técnicas reguladas" (1975, p. 227) y fue una matriz fundamental en la constitución de las ciencias empíricas y los saberes experimentales. De modo similar a lo sucedido entre el poder soberano y la investigación, el examen se transformó en la técnica de saber propia de las disciplinas pero, y aquí viene la referencia que 
incluyen Golder y Fitzpatrick, "la gran investigación que ha dado lugar a las ciencias de la naturaleza se ha separado de su modelo político jurídico; el examen, en cambio, está siempre inserto en la tecnología disciplinaria" (Foucault, 1975, p. 228). No es posible explicar cómo de este pasaje, en el cual Foucault presenta un modelo jurídico político y un modelo disciplinario con sus respectivas formas de constitución de saber, e indica que mientras los saberes experimentales se desligaron de su matriz jurídico-política no ha ocurrido lo mismo con el examen -propio de las disciplinas-, los autores postulan que el objeto de estudio de Vigilar y castigar es el "modelo jurídico-político" de la sociedad.

A pesar de estos problemas, Golder y Fitzpatrick creen que para analizar las relaciones entre la ley, el poder, y los saberes, no solamente no hay que considerar a la ley como autosuficiente, sino que hay que entender que las disciplinas y el biopoder tampoco lo son. Por ello hay que demostrar "la relación necesaria que existe entre ley y poder" (2009, p. 61) para lo cual se abordan dos ejemplos: 1- la vinculación entre el poder disciplinario y las ciencias del hombre; 2- la respuesta del poder disciplinario al sujeto indócil [recalcitrant].

1- Foucault no establece una relación mono-causal entre poder disciplinario y ciencias del hombre, sino que muestra cómo la emergencia de las ciencias del hombre está ligada al surgimiento de las disciplinas, pero el funcionamiento de éstas también dependen de la constitución de un saber sobre el hombre. Empero, como el proyecto de las ciencias humanas de conocer la individualidad y la sociedad no es completo cabe preguntarse ¿qué es lo que ayuda a (re)constituir el poder disciplinario y las ciencias del hombre? "La respuesta, o una de las posibles respuestas, Foucault nos dice, es la ley" (Golder, Fitzpatrick, 2009, p. 63). Para sustentar esta postura los autores recuerdan que en Vigilar y castigar se lee que "los controles de normalidad estaban fuertemente encuadrados por una medicina y una psiquiatría que les garantizaban una forma de «cientificidad»; estaban apoyados sobre un aparato judicial que, de manera directa o indirecta, les aportaba su garantía legal" (Foucault, 1975, p. 302). Una de las maneras mediante las cuales la ley constituye la autoridad del poder disciplinario es actuando como su límite, y en la medida en que hay una intervención judicial cuando se produce un exceso del poder disciplinario, se nota que "la disciplina está aquí constitutivamente dependiente de la ley, que la frena en sus excesos" (Golder, Fitzpatrick, 2009, pp. 64-65). Aunque no comprendo por qué el ejemplo se incluye a propósito de la relación entre el poder disciplinario y las ciencias del hombre, ni cómo la ley solucionaría las deficiencias en el conocimiento de la individualidad, el problema es más grave: tal como insistiré más adelante, incluso suponiendo la relación constitutiva entre disciplinas y leyes, no se encuentran elementos que desechen el carácter secundario y prohibitivo de la ley subrayado por la tesis de la expulsión.

2- Estudiando la relación entre el poder disciplinario y la indocilidad, Golder y Fitzpatrick notan que las disciplinas se apoyan en la ley para hacer frente a la insubordinación. La indocilidad no puede ser contenida en su totalidad por la norma: ella es inevitable y a la vez indispensable para el fomento del poder disciplinario, pero "hay un punto en el cual esas formaciones disciplinarias fracasan en hacer frente a la resistencia" (2009, pp. 69-70). Las disciplinas logran identificar comportamientos anormales pero carecen de mecanismos para aplicar sanciones, por lo que deben recurrir a otra modalidad: "en el indócil, límite de la disciplina, se 
posiciona la ley, una ley que debe estar dentro de la escena disciplinaria pero también mantenerse separada" (2009, p. 70).

Aunque a primera vista el razonamiento parece atractivo, resultan problemáticos los pasajes de Vigilar y castigar que se incluyen para sustentar que la ley interviene como reacción a la indocilidad. Golder y Fitzpatrick recuerdan que Foucault sostiene que en el centro de los "sistemas disciplinarios, funciona un pequeño mecanismo penal. Beneficia con cierto privilegio de justicia, con sus propias leyes, sus delitos específicos, sus formas particulares de sanción, sus instancias de juicio" (Foucault, 1975 , p. 180). Si bien con estas líneas no queda claro cómo las disciplinas se valen del sistema legal, lo problemático es que recortan el párrafo y no agregan que en el régimen disciplinario el arte de castigar "se opone, pues, término a término una penalidad judicial" (Foucault, 1975, p. 185). La penalidad judicial no refiere a fenómenos observables sino a leyes que hay que memorizar, no diferencia individuos sino que especifica los actos bajo un cierto número de categorías, no jerarquiza sino que hace jugar la oposición binaria permitido/prohibido. Es así que, "los dispositivos disciplinarios han secretado una "penalidad de la norma», que es irreductible [cursiva agregada] a los principios y su funcionamiento a la penalidad tradicional de la ley" (Foucault, 1975, p. 185). Realmente no se entiende cuál es la apuesta teórica de Golder y Fitzpatrick al restituir una referencia que, leída en su totalidad, diferencia el castigo disciplinario del castigo judicial y legal, y nada agrega cómo la ley actúa ante la indocilidad.

Golder y Fitzpatrick pretenden seguir sustentando su tesis y reseñan que las disciplinas "en apariencia, no constituyen más que un infra-derecho" (Foucault, 1975, p. 224). Sin embargo es curioso que no agreguen aquello que Foucault incluye casi a continuación: a primera vista las disciplinas parecen prolongar a nivel particular las formas generales del derecho, constituyendo el mismo derecho pero a menor escala. De todos modos, descartando esta primera impresión, más que un infraderecho "hay que ver en las disciplinas una especie de contra-derecho [cursiva agregada]" (1975, p. 224). Las disciplinas ponen en funcionamiento notables disimetrías y con ello "efectúan una puesta en suspenso, jamás total, pero tampoco anulada, del derecho. Por tan regular e institucionalizada que sea, la disciplina, en su mecanismo, es un "contra-derecho»" (1975, p. 224). ${ }^{1}$ Es imposible entender cómo los autores se quedan con esa primera impresión de las disciplinas como "infra-derecho" y no advierten el esfuerzo de Foucault de mostrar lo contrario: que son un "contra-derecho". Con estas torpes referencias creen estar en condiciones de postular que "la forma jurídica está constantemente inscripta dentro de la tecnología disciplinaria del poder" (Golder, Fitzpatrick, 2009, p. 70). Sin embargo, si se leen las referencias completas, no solamente no se advierte esta inscripción sino más bien un intento por dar cuenta de las notables diferencias entre la ley y las disciplinas.

Golder y Fitzpatrick agregan que al describir "una norma que ha recurrido a lo jurídico en el momento final de indocilidad, Foucault está demostrando la dependencia de las disciplinas respecto de la ley [...] es entonces en el límite de la indocilidad generativa que la cientificidad de las normas cede paso a la aplicación

\footnotetext{
${ }^{1}$ Es así que "si el juridicismo universal de la sociedad moderna parece fijar los límites al ejercicio de los poderes, su panoptismo por todos lados expandido hace funcionar, en sentido contrario del derecho, una maquinaria a la vez inmensa y minúscula que sostiene, refuerza, multiplica la disimetría de los poderes y, vuelve vanos los límites que se le han trazado [...] Ellas han sido, en la genealogía de la sociedad modera, con la dominación de clase que la atraviesa, la contrapartida política de las normas jurídicas según las cuales se redistribuía el poder" (1975, pp. 224- 225).
} 
jurídica de la ley" (2009, p. 70). Si bien volveré sobre la relación entre indocilidad y ley, es problemático focalizarse en la indocilidad que generan los mecanismos disciplinarios sin tematizar sobre aquello que en El poder psiquiátrico Foucault había calificado como "residuos". Allí postulaba que las instituciones disciplinarias generaban en su seno individuos que no se ajustaban a los parámetros de normalidad, que no podían clasificarse, que "escapaban a la vigilancia" (2003, p. 55). Generaban casos parecidos a la indocilidad, ${ }^{2}$ pero de modo bien distinto a lo que plantean Golder y Fitzpatrick, a quienes no se ajustaran al parámetro de normalidad no les esperaba la ley sino otro dispositivo disciplinario (Foucault, 2003, p. 56). Resulta todavía más extraño que los autores no analicen el resumen del curso sobre Los anormales, dónde específicamente se expone la situación del niño indócil. Foucault desarrolló la genealogía del individuo anormal que emerge en el siglo XIX, descendiente del monstruo, el onanista y el individuo a corregir (1999, pp. 51-55). Aunque no fue tematizado en el curso, en el resumen aparece una referencia al indisciplinado, una figura más tardía que la del monstruo y que a diferencia de éste no es correlato de la ley. Más bien, "la aparición del incorregible es contemporánea a la puesta en práctica de las técnicas de disciplina [...] Los nuevos procedimientos de encauzamiento del cuerpo, del comportamiento y de las aptitudes inauguran el problema de quienes escapan a esta normatividad que ya no es la soberanía de la ley [cursiva agregada]" (2001a, p. 1692). Los incorregibles son aquellos que escapan a una normatividad que no es la ley, que a su vez es asociada a la prohibición: "la "prohibición» constituía la medida judicial mediante la cual un individuo era, al menos parcialmente, descalificado como sujeto de derecho" (2001a, p. 1692). Reduciendo el marco jurídico a un dispositivo negativo, y mostrando que no son las leyes sino los métodos positivos del enderezamiento los que actuarán sobre el indócil, Foucault subraya que "ese marco, jurídico y negativo, va a ser en parte ocupado y en parte reemplazado por un conjunto de técnicas y procedimientos con los que se emprenderá encauzar a aquellos que se resisten al encauzamiento y corregir a los incorregibles" (2001a, p. 1692). Mientras el Foucault que presentan Golder y Fitzpatrick muestra que la ley se pone en funcionamiento ante la presencia de individuos indóciles, el Foucault que se lee en el resumen de Los anormales enfatiza que para responder a la indocilidad la ley fue ocupada y reemplazada por las disciplinas.

Golder y Fitzpatrick observan una correlación entre la ley y las disciplinas, pero para sustentarlo realizan una presentación muy problemática de Vigilar y castigar, analizan la relación entre disciplinas e indocilidad sin abordar El poder psiquiátrico ni el resumen de Los anormales, y construyen un relato imaginario sobre el funcionamiento de la ley. Empero, suponiendo que las anteriores dificultades pueden salvarse, con su defectuosa exposición no logran desterrar la tesis de la expulsión: 1. Incluso asumiendo que las disciplinas necesitan de las leyes, esto no implica que tengan un rol predominante en el diagrama de poder moderno. De hecho, en Seguridad, territorio, población Foucault (2004, p. 111) indica que no hay una sustitución de la soberanía por las disciplinas y de los dispositivos de seguridad por sobre ellas, sino que en un momento histórico determinado se desarrolla una predominancia de uno de los mecanismos sobre los otros. De este modo, nada de aquello que con tramposas referencias postulan Golder y Fitzpatrick nos permite desechar este segundo plano que tendría la ley en el diagrama de poder la

\footnotetext{
${ }^{2}$ Como ejemplos de estos "residuos" Foucault (2003, pp. 55-56) incluye al desertor del ejército quien al no ajustarse a la disciplina militar puede tenerse como un caso de indocilidad.
} 
modernidad. 2. En consonancia con lo anterior, tampoco logran desterrar la hipótesis del funcionamiento meramente prohibitivo de la ley. Asumiendo la supuesta relación entre las disciplinas y la ley, ésta podría seguir funcionando de modo represivo, algo que puede ilustrarse realizando un paralelismo con el accionar de la familia. En El poder psiquiátrico Foucault indica que la familia fijaba a los individuos a las instituciones disciplinarias -obligando a los niños a ir a la escuela, a los jóvenes a realizar el servicio militar-, y era una bisagra entre las diferentes instituciones porque permitía el pasaje de un sistema disciplinario a otro -enviaba al indócil escolar al reformatorio (1999, pp. 82-84)-. La familia tenía un papel importante en el funcionamiento de las sociedades disciplinarias pero no por ello funcionaba de modo disciplinario, sino que actuaba de acuerdo con un modelo soberano de poder, manteniendo un esquema de individualización del poder en la cima -en el padre- y sin tener a la vigilancia como constitutiva de su organización (1999, pp. 81-82). Que una institución, sea la ley o la familia, se vincule con las disciplinas no implica que funcione bajo una racionalidad disciplinaria.

En el primer paso del trabajo de Golder y Fitzpatrick encontramos que el sustento para postular una íntima relación entre la ley y los dispositivos de disciplinarios no es otro que una problemática, y hasta tramposa, presentación de la obra de Foucault. Sin embargo, incluso asumiendo la relación entre disciplinas y derecho, no queda claro si éste funciona de modo prohibitivo o productivo, ni si ocupa un rol fundamental o secundario en el diagrama de poder. De todos modos, luego de este primer paso fallido, los autores se proponen avanzar en la especificidad de la ley. Sin embargo este avance también fracasa.

\section{III.a. La receptividad de la ley}

Luego de enunciar la interdependencia entre la ley y los poderes externos, Golder y Fitzpatrick sostienen que Foucault presenta dos dimensiones de la ley: a- una que expresa un contenido definido y que podría tenerse como una ley al costado de la norma, b- otra que tiene un compromiso con las resistencias y las transgresiones, y se extiende tratando de responder a aquello que yace por fuera de su contenido (2009, p. 71). Existen dos dimensiones: "la ley determinada, y la ley receptiva [responsive] que está siempre inclinada más allá de sí misma, sensible a ser deshecha por la resistencia" (2009, p. 72). Caracterizarla a partir de su rigidez pero también de su capacidad de ser avasallada no representa una contradicción sino dos modalidades de la misma ley (2009, p. 72), y Golder y Fitzpatrick reconstruyen el carácter receptivo de la ley, para lo cual avanzan sobre la relación entre poder y resistencia, y entre transgresión y límite.

Golder y Fitzpatrick (2009, pp. 74-75) subrayan la centralidad que en las relaciones de poder tiene la resistencia, puesto que ella es lo primero (Foucault, 2001b, p. $1560)$. Donde hay poder hay resistencia, y ésta no es una simple reacción externa del poder sino que lo constituye. De hecho, teniendo en cuenta los desarrollos de El sujeto $y$ el poder, ${ }^{3}$ en lugar de concebir a la resistencia como respuesta al poder "Foucault ve al poder mismo como respuesta a (y genéticamente formada por) la resistencia" (Golder, Fitzpatrick, 2009, p. 75).

\footnotetext{
${ }^{3}$ Allí Foucault indicaba que su analítica del poder tenía como punto de partida el análisis de "las formas de resistencia contra las diferentes formas de poder" (1983, p. 211). Además, esto suponía que "la libertad puede muy bien aparecer como condición de existencia del poder" (1983, p. 211).
} 
Aunque Golder y Fitzpatrick no equiparan la transgresión a la resistencia, entienden que la relación entre la resistencia y las formaciones de poder ya figura en las reflexiones sobre la "transgresión" y el "límite" que Foucault despliega en la década de 1960. De estos trabajos se desprende que "la transgresión constituye, ella misma, al límite" (Golder, Fitzpatrick 2009, p. 77) y así como el poder es una reacción a la resistencia, la transgresión compone y recompone el límite. En este marco la ley es caracterizada como carente de solidez, irreductible a la expresión de una regla, ya que asume "una existencia lábil, y esto es lo que hemos estado denominando receptividad de la ley en Foucault" (Golder, Fitzpatrick, 2009, p. 77). Lo novedoso del trabajo de los autores es rastrear esta dimensión receptiva en dos trabajos poco frecuentados por quienes abordan el problema de la ley: Prefacio a la transgresión, publicado en 1963, El pensamiento del afuera, de 1966.

Foucault tematizó sobre el carácter receptivo de la ley en El pensamiento del afuera cuando, en el marco de la presentación de dos novelas de Maurice Blanchot, aludió a una "ley de mutabilidad", una ley que practica una "silenciosa e indefinidamente complaciente bienvenida" (2001c, p. 559) hacia lo que se sitúa fuera de ella. Nunca estable, la ley "más que el principio o la prescripción interna de las conductas, es el afuera que las envuelve, y que por ello las hace escapar a toda interioridad" (2001c, p. 557). La ley está en constante movimiento, envolviendo aquello que pretende voltearla, y entonces Foucault se pregunta: “¿Cómo se podría conocer la ley y experimentarla verdaderamente, cómo se la podría obligar a tornarse visible, a ejercer claramente sus poderes, a hablar, si no se la provocara, si no se la forzara en sus reductos, si no se marchara decididamente siempre más lejos hacia el afuera donde siempre está más retirada?" (2001c, p. 557).

En este caso, y excepcionalmente, la presentación que realizan los autores es precisa pero uno podría preguntarse: ¿Qué vinculación tiene un trabajo escrito en 1966, cuando Foucault todavía no había desplegado su analítica del poder, con la relación entre la ley y el biopoder? ¿Qué nos aporta un trabajo en el cual no se expone la mirada de Foucault sobre la ley, sino uno reconstrucción de las observaciones que sobre ella se desprenden de dos novelas de Blanchot? Para responder a estas preguntas los autores vuelven a Vigilar y castigar y a La voluntad de saber, pero incluyen argumentos sacados completamente de contexto.

Para Golder y Fitzpatrick, la ley se encuentra constitutivamente articulada con la exterioridad por lo que no está " "dada de una vez y para siempre»" (2009, p. 78) sino que se encuentra en negociación con los poderes que la asedian desde afuera. La referencia textual "dada de una vez y para siempre" la extraen de La voluntad de saber con la intención de trazar una continuidad entre El pensamiento del afuera y los estudios sobre el biopoder. Sin embargo, la frase está en medio de una pregunta que no tiene relación con la ley: “¿Cómo el juego de esas relaciones de poder [las que pesan sobre la sexualidad] se encontró modificado por su propio ejercicio refuerzo de ciertos términos, debilitamiento de otros, efectos de resistencia, contra cargas-, de suerte que no ha habido, dado de una vez y para siempre, un tipo estable de sujeción?" (Foucault, 1976, p. 129). Con la línea que incluyen Golder y Fitzpatrick parece correcto el paralelismo entre los trabajos del decenio de 1960 y La voluntad de saber, pero si se lee la pregunta completa todo pierde sentido.

Así como en El pensamiento del afuera refiere a una ley que está orientada hacia el afuera, siempre de acuerdo con Golder y Fitzpatrick, en Vigilar y castigar se lee que "es destino del derecho absorber poco a poco elementos que le son extraños" 
(Foucault, 1975, p. 27). De todos modos, es importante advertir que cuando Foucault realiza esta afirmación alude a una situación por la cual, a partir de los siglos XVIII y XIX los jueces se vieron en la situación de juzgar algo distinto de simples delitos, y el funcionamiento judicial se cargó de operadores extrajurídicos, contexto en el que indica que esa situación tal vez no sea extraordinaria porque quizás sea el destino del derecho. Sin embargo, luego aclara que hay algo muy particular en la justicia penal moderna: "si ella se carga tanto de elementos extrajurídicos, no es para poder calificarlos jurídicamente e integrarlos poco a poco al estricto poder de castigar: es, al contrario para poder hacerlos funcionar al interior de la operación penal como elementos no jurídicos [cursivas agregadas]; es para evitar que esta operación sea pura y simplemente un castigo legal [cursivas agregadas]" (1975, p. 27). Entre los elementos extraños se destaca la psiquiatría, y Foucault remarca que la justicia penal no los transforma en jurídicos. La existencia de estos elementos, al contrario de lo que suponen Golder y Fitzpatrick, no hacen que la ley se transforme, recepte el afuera, absorba elementos extraños, sino que éstos se mantienen por fuera de la ley, y eso hace que el castigo no sea "simplemente un castigo legal." Para Foucault, "la maquinaria penal no funciona solamente con una ley" (2001d, p. 444).

Aunque la mayoría de los comentadores indican que Foucault ofrece una mirada estática de la ley, ésta es solamente una de sus facetas, a la que hay que agregar su dimensión "receptiva", que la hace abierta a nuevas posibilidades. El objetivo de Golder y Fitzpatrick es articular las dos dimensiones, no en vistas de corregir una supuesta inconsistencia, "sino más bien en el interés de observar una inconsistencia constitutiva -o irresolución- en el objeto teórico de Foucault: la ley" (2009, pp. 7980). Incluso para que la ley brinde certidumbre y previsión, debe ser receptiva a su exterior y relacionarse con los cambios socioeconómicos. No estamos frente a dos variables opuestas sino complicadas: "la receptividad de la ley es generadora o productora de la determinación de la ley, y viceversa" (2009, p. 81). Como la ley se encuentra abierta a nuevas posibilidades, siguiendo a Bob Fine, Golder y Fitzpatrick postulan que ella presenta una "forma vacía" (Fine, 1984, p. 200). Según indican, Foucault alude a la ley como una "sustancia impalpable", una "ausencia," pero al momento de sustentarlo vuelven a referenciar El pensamiento del afuera, donde Foucault presenta la mirada que se extrae de la ley en dos novelas de Blanchot. De todos modos, a su lista de desordenadas referencias suman un pasaje de Nietzsche, la genealogía, la historia, en donde se lee que las reglas están vacías, algo que tiene consecuencias para las leyes, puesto que "ellas están hechas para servir a esto o a aquello; ellas pueden ser doblegadas a gusto de tal o cual" (Foucault, 2001e, p. 1013). Sin embargo el recorte del párrafo no resulta apropiado porque en ese pasaje Foucault continúa hablando de las reglas, no de las leyes. ${ }^{4}$

Es por su carácter constitutivamente vacío que la ley puede ser instrumentalizada por poderes externos, y Foucault ha mostrado cómo fue utilizada tanto por el funcionamiento soberano del poder cuanto por las estrategias gubernamentales. Los suplicios son un ejemplo de cómo la ley necesita de poderes externos para tener

\footnotetext{
${ }^{4}$ El párrafo entero dice: "Y es justamente la regla la que permite que se haga violencia a la violencia, y que una otra dominación pueda plegarse a aquellos mismos que dominan. En sí mismas las reglas están vacías, violentas, no finalizadas; ellas están hechas para servir a esto o aquello; pueden ser empleadas a voluntad de tal o cual. El gran juego de la historia, es quién se amparará de las reglas, quién ocupará la plaza de aquellos que las utilizan, quién se disfrazará para pervertirlas, utilizarlas a contrasentido y volverlas contra aquellos que las habían impuesto; quién, introduciéndose en el complejo aparato, lo hará funcionar de tal modo que los dominadores se encontrarán dominados por sus propias reglas" (Foucault, 2001e, pp. 1013-1014).
} 
efecto, pero en la modernidad la ley fue penetrada por el poder disciplinario. Para sustentar esta tesis, citando Vigilar y castigar, los autores subrayan que los procedimientos disciplinarios "van poco a poco a invadir esas formas [legales] mayores, modificando sus mecanismos e imponiendo sus procedimientos" (Foucault, 1975 , p. 172$)^{5}$. Sin embargo, la referencia es tramposa puesto que esas "formas mayores" no son las legales que los autores implantan con sus corchetes en la cita, sino los aparatos de Estado. Es así que en la oración anterior, Foucault indica que los procedimientos disciplinarios son "humildes modalidades, procedimientos menores, si se los compara con los rituales majestuosos de la soberanía o los grandes aparatos del Estado" (1975, p. 172). En la prolija comprensión de Vigilar y castigar, los procedimientos disciplinarios invaden a los aparatos del Estado -que no necesariamente operan con la ley-, y no a las leyes -tal como Golder y Fitzpatrick [nos] confunden-.

\section{III. b. La ley y el lazo social}

La vacuidad de la ley es polivalente, y "la hace abierta a la apropiación y dominación, y simultáneamente, la hace abierta a una resignificación y renovación que elude la determinación de la soberanía o un régimen político dado" (Golder, Fitzpatrick, 2009, p. 84). Golder y Fitzpatrick entienden que por su capacidad de reaccionar ante lo contingente la ley es un componente constitutivo del lazo social en la modernidad, y aunque no es algo que haya sido explícitamente enunciado por Foucault puede reconstruirse de parte de su producción.

En Prefacio a la transgresión Foucault caracteriza a la modernidad como la muerte de Dios, y la negación de los vínculos con un mundo trascendente abre la pregunta por la organización social, para lo cual pueden reconstruirse dos respuestas: modernidad como clausura y modernidad como ruptura. La primera refiere a una mirada de la modernidad en donde todo parece estar disciplinado, a la cual le corresponde la idea de "ley social" acuñada por François Ewald que presenta una legalidad de compromisos y estabilidad (Golder, Fitzpatrick, 2009, p. 102). Por otra parte, en ¿Qué es la llustración? Foucault define a la modernidad como una actitud respecto del presente, que implica imaginarlo de otro modo, acompañada de una crítica de nuestro ser actual. La crítica es un ethos que indaga lo que somos, los límites que se nos imponen, y la posibilidad de atravesarlos para crear nuevos modos de vida. ${ }^{6}$ Ahora, para Golder y Fitzpatrick, lejos de una modernidad como clausura estamos frente a una modernidad como ruptura, que se corresponde con la "dimensión receptiva de la ley, en su capacidad de abrir la sociedad a la alteridad, a una ética de ser constantemente de otro modo" (2009, p. 109). Bajo este paradigma, la sociabilidad no está dada por la constitución de parámetros de normalidad sino por la posibilidad de transgredirlos, y para que la ley se ajuste a ello debe mantener una dinámica receptiva de otros modos de ser. Así, el argumento central indica que "la ley es una fuente constitutiva de nuestro ininterrumpido estar-juntos, y es precisamente a través de su receptividad que logra eso" (2009, p. 100). Dicho de otra manera, la ley es una configuración "clave de nuestra sociabilidad, de nuestro continuo estar con cada uno. A través de su habilidad para combinar repetidamente

\footnotetext{
${ }^{5}$ Este corchete es incorporado por Golder y Fitzpatrick.

${ }^{6}$ La modernidad "tiene que ser concebida como una actitud, un ethos, una vida filosófica en la que la crítica de lo que somos es al mismo tiempo el análisis histórico de los límites que se nos han impuesto y un experimento con la posibilidad de atravesarlos" (Foucault, 1984, p. 50). Ver también Foucault (2008, pp. 9-22).
} 
una determinada fijación de límites y una receptiva consideración hacia esos límites y su reformulación, la ley provee una apertura hacia el futuro" (2009, p. 125).

Aunque subrayan que la dimensión constitutiva de lo social que posee la ley no ha sido tematizada por Foucault, Golder y Fitzpatrick creen que puede rastrearse en La verdad y las formas jurídicas. Allí Foucault inicia el desarrollo histórico de las formas jurídicas con una presentación de La Ilíada, donde la disputa entre Menelao y Antíloco se lleva adelante no a través de una investigación sino de un juramento, de un juego de pruebas. Luego se incluyen pasajes de Edipo rey, que marca la transición desde la prueba de la verdad hacia la indagación, según la cual la verdad del crimen se establece por un testimonio. En la lectura que hacen Golder y Fitzpatrick (2009, pp. 126-129) esas prácticas jurídicas serían constitutivas de las formas de la sociedad griega, por lo que la ley no solamente provee un mecanismo para afirmar la verdad en una controversia, sino que representa la verdad del lazo social. La ley es el punto de partida de las formas de conocimiento y de la organización social.

Si bien a primera vista la presentación de las conferencias parece ordenada, la primera aclaración que hay que hacer es que Foucault no asienta en la ley el punto de partida de las formas de conocimiento -ni de la organización social- sino en prácticas sociales. Recordemos que la apuesta general de las conferencias era "mostrar cómo las prácticas sociales [cursivas agregadas] pueden llegar a engendrar dominios de saber que no solamente hacen aparecer nuevos objetos, nuevos conceptos, nuevas técnicas, sino también hacen nacer formas totalmente nuevas de sujetos y de sujetos de conocimiento" (2001f, p. 1404). En el caso de Grecia esas prácticas sociales constitutivas del conocimiento eran prácticas jurídicas pero nunca meras leyes, y Golder y Fitzpatrick no solamente no explican cómo una ley que es punto de partida para la formación de un saber es constitutiva del lazo social sino que, una vez más, fallan en la presentación de los desarrollos del autor francés. Sin embargo, lo más problemático es que cuando analiza la formación del conocimiento en la modernidad, Foucault abandona el terreno de las prácticas jurídicas para enfocarse en las prácticas disciplinarias, de control y vigilancia, que poco tienen que ver con aquellas. En este sentido, estaba especialmente interesado en rastrar cómo se ha formado "un determinado saber del hombre, de la individualidad, del individuo normal o anormal, dentro o fuera de la regla, un saber que, en verdad, ha nacido de las prácticas de control y de vigilancia" (2001f, p. 1407) ${ }^{7}$. La formación del conocimiento en la modernidad se construye lejos de la ley, por lo que para sustentar ese supuesto papel constitutivo que tiene la ley en los lazos sociales, Golder y Fitzpatrick vuelven a defraudar en su presentación de la obra de Foucault.

\section{Notas finales}

Dentro de los pocos trabajos que analizan la relación entre el diagrama de poder y la ley al interior de la obra de Foucault, una buena parte de las discusiones giran

\footnotetext{
${ }^{7}$ Foucault postuló que en el marco de las prácticas de vigilancia desarrolladas en las instituciones disciplinarias se extrae un saber que los mismos individuos producen, por ejemplo al realizar sus tareas cotidianas, pero también allí nace "un saber de observación, un saber de algún modo clínico, como el de la psiquiatría, de la psicología, de la psicosociología, de la criminología" (2001e, p. 1488). De este modo, el poder disciplinario "ha provocado el nacimiento de una serie de saberes -saber del individuo, de la normalización, saber correctivo- que se multiplicaron en esas instituciones de subpoder, haciendo aparecer las susodichas «ciencias del hombre», y el hombre como objeto de la ciencia" (2001e, p. 1490).
} 
alrededor del carácter principal o secundario de la ley. La tesis de la expulsión sostiene que dado el carácter represivo y prohibitivo de la ley, ésta quedó replegada en un segundo lugar en un diagrama de poder que funciona en términos eminentemente productivos. Por su lado, las distintas tesis de la inclusión han remarcado que la ley se inscribe en los dispositivos disciplinarios y en las tecnologías gubernamentales. En este contexto, el trabajo de Ben Golder y Peter Fitzpatrick irrumpe con una notable potencia. Por un lado porque desarrollan una lectura integral de la obra de Foucault, y por otro porque tratan de rescatar otra ley de Foucault. Postulan una intensa correlación entre las disciplinas y la ley, a la vez que anuncian un carácter vacío de esta última. Profundizan en la relación entre la ley y las relaciones de poder, pero también entre la ley y las prácticas de resistencia, paradigma en el cual enuncian que la ley constituye el lazo social de la modernidad. A primera vista, entonces, Foucault's Law representa una muy interesante novedad en las lecturas de la ley al interior de la obra del autor francés. Sin embargo, un estudio más detallado muestra que esta novedad pierde potencia porque la presentación de Foucault es realmente muy problemática y hasta tramposa. Esto no implica suscribir la tesis de la inclusión ni tampoco las tesis de la inclusión, sino que obliga a seguir pensando la relación entre la ley y el poder al interior de la obra de Foucault. Y sobre la relación entre la ley y el poder, a pesar de la obra de Foucault.

\section{Referencias}

Beck, A, (1996). Foucault and Law: The Collapse of Law's Empire. Oxford Journal of Legal Studies 16, 3, pp. 489-502.

Ewald, F. (1986a). The Law of Law. En G. Teubner (Ed.), Autopoietic Law: A New Approach to Law and Society (pp. 36-50). New York and Berlin: De Gruyer.

(1986b) A concept of social law. En G. Teubner (Ed.), Dilemmas of Law in the Welfare State (pp. 40-75). New York and Berlin: De Gruyer.

(1986c). L'Etat providence. Paris: Bernard Grasset.

Fine, B. (1984). Democracy and the Rule of Law: Liberal Ideas and Marxists Critiques. London \& Sidney: Pluto Press.

Foucault, M. (1975). Surveiller et punir. Paris: Gallimard.

(1976). Histoire de la sexualité I. La volonté de savoir. Paris: Gallimard.

(1983). The Subject and Power. En H. Dreyfus, P. Rabinow (Eds.) Michel Foucault: Beyond Structuralism and Hermeneutics (pp. 208-226). Chicago: The University of Chicago Press.

(1984). What is Enlightenment? En P. Rabinow (Ed.) The Foucault Reader (pp. 3250). New York: Pantheon Books.

(1999). Les anormaux. Cours au Collège de France (1974-1975). Paris: Gallimard. (2001a). Les anormaux. En Dits et écrits I ( $n^{\circ} 165$, pp. 1690-1696). Paris: Gallimard. (2001b). Michel Foucault, une interview: sexe, pouvoir et la politique de l'identité. En Dits et écrits II ( $\mathrm{n}^{\circ} 358$, pp. 1554-1565). Paris: Gallimard.

(2001c). La pensé du dehors. En Dits et écrits I ( $n^{\circ} 38$, pp. 546-567). Paris: Gallimard. 
(2001d). L'évolution de la notion d'individu dangereux' dans la psychiatrie légale du XIX siècle. En Dits et écrits II ( $n^{\circ} 220$, pp. 443-464). Paris: Gallimard.

(2001e). Nietzsche, la généalogie, I'histoire. En Dits et écrits I ( $n^{\circ} 84$, pp. 10041024). Paris: Gallimard.

(2001f). La vérité et les formes juridiques. En Dits et écrits I ( $n^{\circ} 139$, pp. 1406-1514). Paris: Gallimard.

(2003). Le pouvoir psychiatrique. Cours au Collège de France (1973-1974). Paris: Gallimard.

(2004). Sécurité, territoire, population. Cours au Collège de France (1977-1978). Paris: Gallimard.

(2008). Le gouvernement de soi et des autres. Cours au Collège de France (19821983). Paris: Gallimard.

Golder, B., Fitzpatrick, P. (2009). Foucault's Law. London: Routledge.

Hirst, P. (1986). Law, Socialism and Democracy. London: Allen \& Unwin.

Hunt, A. (1992a). Foucault's Expulsion of Law: Towards a Retrieval. Law and Social Inquiry, 17, 1, pp. 1-38.

(1992b). Law and the Condensation of Power. Law and Social Inquiry, 17,1, pp. 5762.

Kennedy, D. (1991). The Stakes of Law, or Hale and Foucault! Legal Studies Forum 25, 4, pp. 327-366.

Tadros, V. (1998). Between Governance and Discipline: The Law and Michel Foucault. Oxford Journal of Legal Studies 18, 1, pp. 75-103.

Sousa Santos, B. (2002). Toward a New Legal Common Sense. Law, Globalization, and Emancipation. London: Butterworths-Lexis Nexis.

Rose, R., Valverde, M. (1998). Governed by Law? Social and Legal Studies 7, 4, pp. 541-551.

Wickham, G. (2002). Foucault and Law. En R. Banakr, M. Travers (Eds.), An Introduction to Law and Society Theory (pp. 217-232). Oxford: Hart.

(2006). Foucault, Law and Power: A Reassessment. Journal of Law and Society, 33, 4 , pp. 596-614. 